\title{
Innovation And Designing As Per Industry Need A Survey On Evaluation Criteria Of Curriculum
}

\author{
Dr K. Surya Narayana ${ }^{1}$, Dr M.V.Narasimha Rao ${ }^{2}$ \\ 1Professor, MBA, MLRIT, suryan568@gmail.com \\ ${ }^{2}$ Professor, MBA, MLRIT, drmvnrao@gmail.com
}

\begin{abstract}
First part of this paper gives the importance of curriculum and what is the benefit of a good curriculum and problem with present syllabus. Examples of teacher's experience are given about content of syllabus of papers taught. In the second part curriculum evaluation is done using selected criteria. Evaluation of curriculum is required for development of present curriculum or designing a new curriculum. The survey brings the issues in the current curriculum based on selected evaluation criteria. Curriculum is synonymous with syllabus. Syllabus is the most important part of Teaching learning mechanism. Specific Objectives of learning and teaching will be associated with the syllabus of every subject. Specific Outcomes of learning are expected once the subject is taught. Thus the syllabus content is the driving force for all Academic particularly Class room activities.

A good curriculum must adapt its education activities and services to serve a dynamic community. In our case Industry is the community where the student will be working after successful completion of his course. Industry is dynamic in nature. It has evolving needs in terms of technological, communication and personal and other skills. The syllabus taught in the classroom should give an overall picture of outside environment and its demands to the students and it should bridge the gap between the student skills and industry demand and needs. The basic problem with syllabus is it gets outdated and no more meets outside demand. It will be losing focus. Student will not be interested to learn .It will not benefit the student. This problem can be overcome by continuous monitoring and evaluation of Curriculum. As the teacher teaches the syllabus he can monitor closely and contribute to update the syllabus by designing the old syllabus, modifying parts or suggesting for an entirely new subject.
\end{abstract}

Keywords: 1.Curriculum, 2.learning mechanism, 3.dynamic community, 4.syllabus

\section{Introduction}

Curriculum is synonymous with syllabus. Syllabus is the most important part of teaching learning mechanism.
Specific Objectives of learning and teaching will be associated with the syllabus of every subject. Specific Outcomes of learning are expected once the subject is taught. Thus the syllabus content is the driving force for all Academic particularly Class room activities. A good curriculum must adapt its education activities and services to serve a dynamic community. In our case Industry is the community where the student will be working after successful completion of his course. Industry is dynamic in nature. It has evolving needs in terms of technological, communication and personal and other skills. The syllabus taught in the class room should give an overall picture of outside environment and its demands to the students and it should bridge the gap between the student skills and industry demand and needs.

The basic problem with syllabus is it gets outdated and no more meets outside demand. It will be losing focus. Student will not be interested to learn. It will not benefit the student. This problem can be overcome by continuous monitoring and evaluation of Curriculum. As the teacher teaches the syllabus he can monitor closely and contribute to update the syllabus by designing the old syllabus, modifying parts or suggesting for an entirely new subject.

Our MBA Experience.

1. Consumer Behaviour and Customer Relationships Management.

Previously the syllabus is about Consumer behaviour only which contained old theories. But the present syllabus contains Customer Relationship 
Management which is the heart of current days business. Not only is that e CRM introduced in the syllabus as nowadays electronic commerce is the order of the day. It helps the student in understanding ecommerce better and the role he has to play in the current situation.

\section{Production and Operations Management}

Some of the techniques like $\mathrm{n}$ jobs 2 machines case are not contemporary in nature as the outside industry is dominated by software industry. More focus is to be given on project management and software tools to monitor the project. Also Contemporary topics like SAP, just in time, Lean production, flexible manufacturing system are to be introduced in the syllabus and given more focus.

\section{Human Resource Management}

Here more focus is on invented theories. But more cases ie the practices of various companies like TATA should be incorporated in the syllabus. Best example is Book by Venkata Ratnam on Performance management. Here also EHRM is to be discussed. Contemporary topics are to be discussed.

\section{Student Activity}

All the time students are observed to be passive learners. They must be made to learn actively. They must be made to participate enthusiastically. This can be achieved by designing student activities in the syllabus itself and giving some weightage to the performance of the activities by student.

\section{Case Study Methodology}

The best way is to adopt case study methodology. Here Cases are to be discussed in the classroom. Here also more student participation is required. Overall the syllabus should be an optimum mix of theoretical concepts and contemporary practices.

\section{Methodology}

A survey is conducted among 20 faculties in the MBA and H\&S Department by demonstrating a survey questionnaire. The questions are choice based. Response yes or good is taken positively. Response for All Right or not so good is taken as zero. Response for No or poor is taken as negative. Overall score is obtained as the sum of all the three categories of responses given by the respondent. Data Analysis is performed by drawing Bar charts and by preparing summary score for responses for 16 questions which is represented in a table. At the end findings, suggestions and conclusions are given based on the analysis.

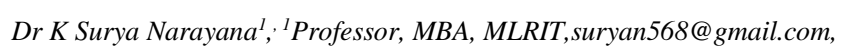

$$
\text { Dr M.V.Narasimha Rao }{ }^{2}
$$

, 2Professor, MBA, MLRIT, drmvnrao@gmail.com 
Table 1.Responses to questions based On evaluation criteria.

\begin{tabular}{|c|c|c|c|}
\hline Evaluation Criteria & $\begin{array}{ll}\text { Yes } & \text { or } \\
\text { Good(+) }\end{array}$ & $\begin{array}{l}\text { All Right but not so } \\
\operatorname{good}(0)\end{array}$ & $\begin{array}{ll}\text { No } & \text { or } \\
\text { poor(-) }\end{array}$ \\
\hline 1. Content covers a significant portion of the course competencies. & 10 & 8 & 2 \\
\hline 2. Content are up-to-date. & 5 & 10 & 5 \\
\hline $\begin{array}{l}\text { 3. Reading level is appropriate for most students who will use the } \\
\text { material }\end{array}$ & 10 & 7 & 3 \\
\hline 4. Intended learning outcomes, competencies are stated. & 7 & 8 & 5 \\
\hline 5. Formative and summative assessments are included. & 10 & 5 & 5 \\
\hline 6. Activities are varied to meet the needs of students. & 3 & 14 & 3 \\
\hline 7. Teacher's guide is included with management suggestions & 3 & 14 & 3 \\
\hline 8. Materials are presented in logical order. & 10 & 5 & 5 \\
\hline 9. Learning outcomes, competencies and/or tasks. & 8 & 8 & 4 \\
\hline $\begin{array}{l}\text { 10. Degree of match between learning activities and intended } \\
\text { learning outcomes }\end{array}$ & 8 & 6 & 6 \\
\hline $\begin{array}{l}\text { 11. Quality of test items and degree of match with intended learning } \\
\text { outcomes. }\end{array}$ & 7 & 7 & 6 \\
\hline $\begin{array}{l}\text { 12.Quality of direction on how students will process through the } \\
\text { materials. }\end{array}$ & 12 & 6 & 2 \\
\hline 13.Quality of drawings, photographs, and/or other materials. & 14 & 3 & 3 \\
\hline 14.Overall design of the learning activities for individual instruction. & 8 & 7 & 5 \\
\hline 15.Quality of management procedures for teachers & 10 & 5 & 5 \\
\hline $\begin{array}{l}\text { 16. Optional (List course map competencies covered by the } \\
\text { instructional Material) }\end{array}$ & 8 & 8 & 4 \\
\hline
\end{tabular}

\section{Graphical Charts}

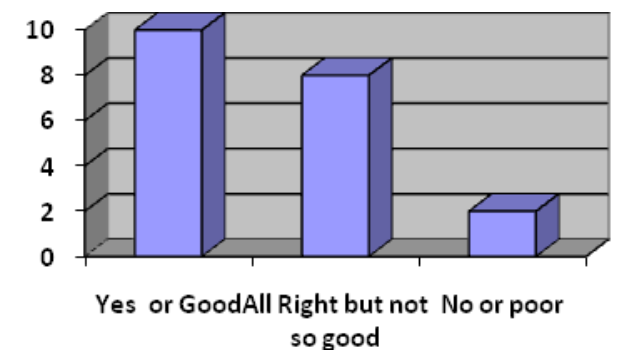

$\square 1$. Content covers a significant portion of the course competencies.

Figure 1: Content Coverage 


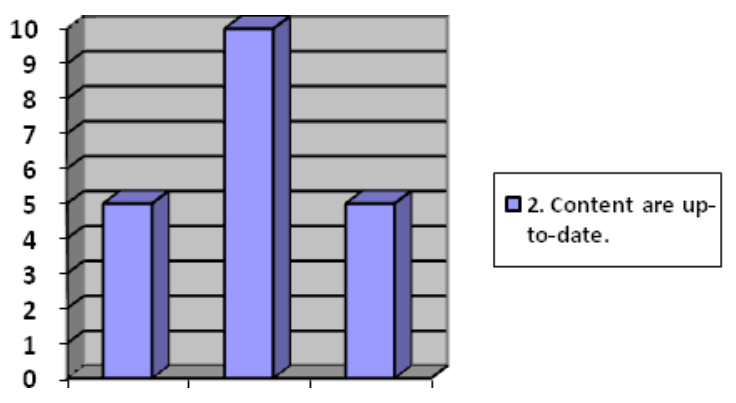

Figure 2: Contents Uptodateness

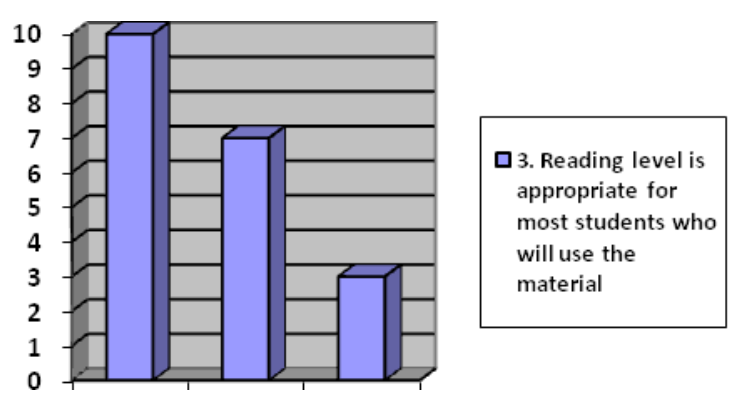

Figure 3: Reading level for the student

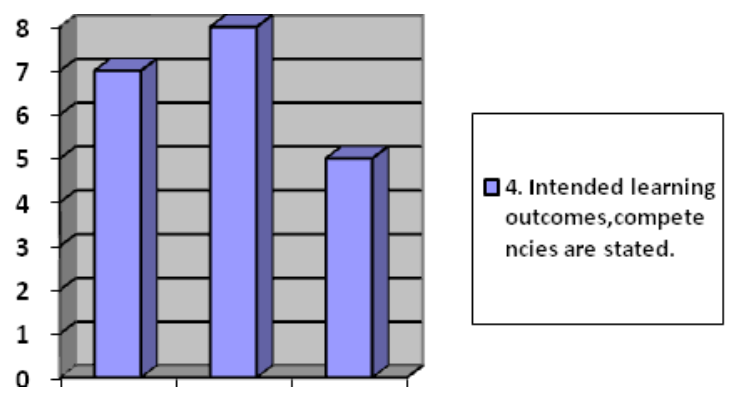

Figure 4: Intended Outcome 


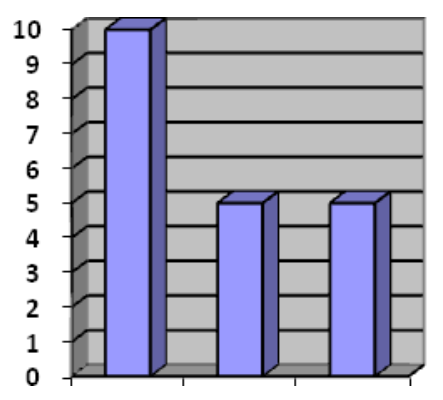

口5. Formative and summative

assessments are

included.

Figure 5: assessments

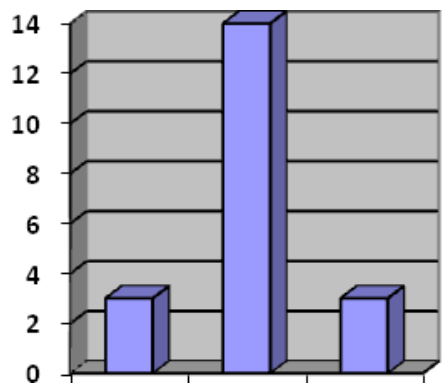

口6. Activities are varied to meet the needs of students.

Figure6:Varying activities

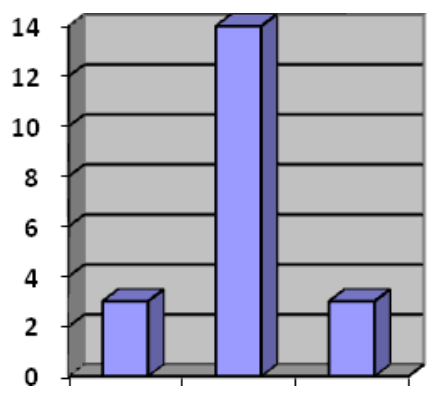

口7. Teacher's guide is

included with

management

suggestions

Figure7: Teachers Guide 


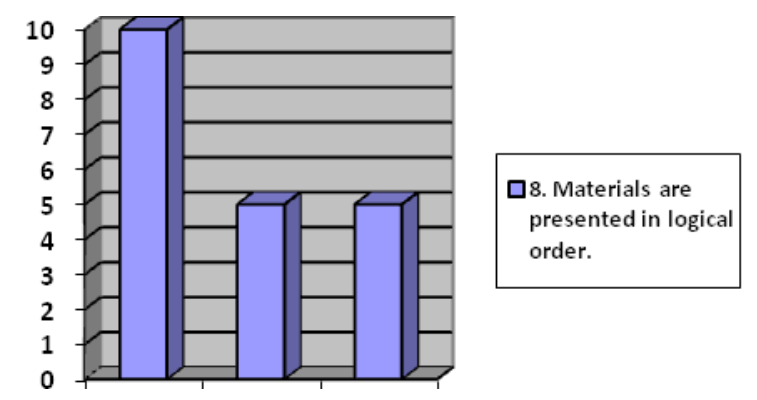

Figure 8; Logical Presentation of material

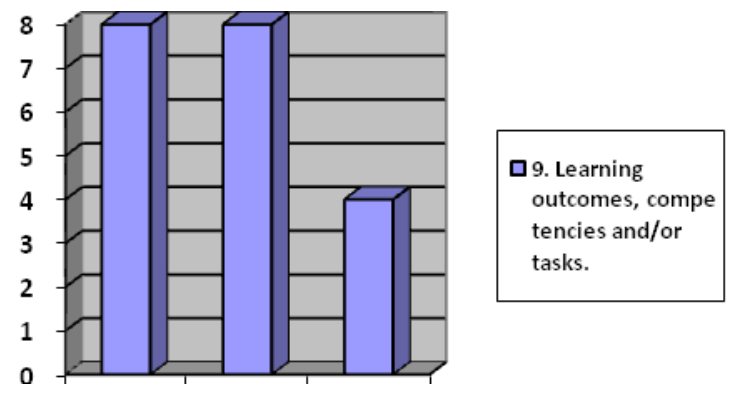

Figure 9: Learning outcomes, competencies and/or tasks

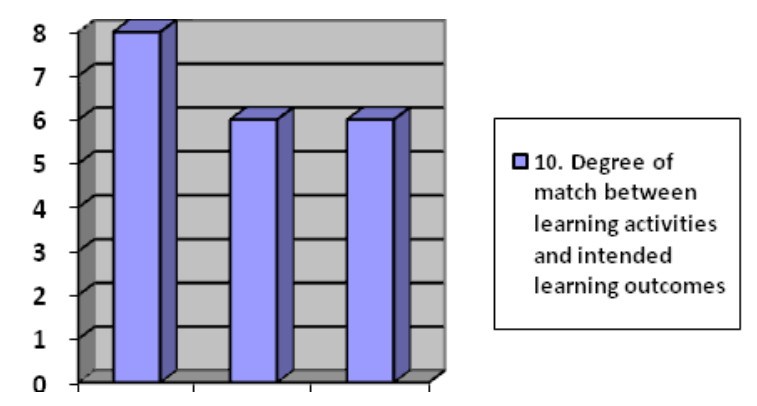

Figure 10: Matching between learning activities and out comes 


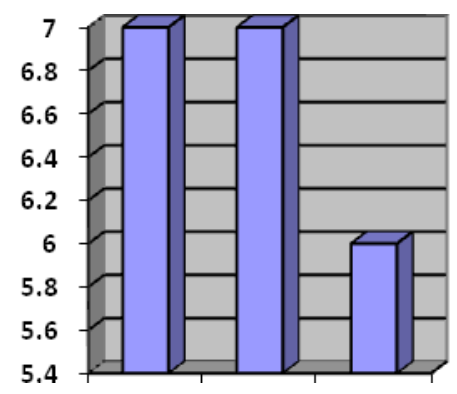

口11. Quality of test items and degree of match with

intended learning outcomes.

Figure 11: Quality of test items and degree of match with intended learning outcomes

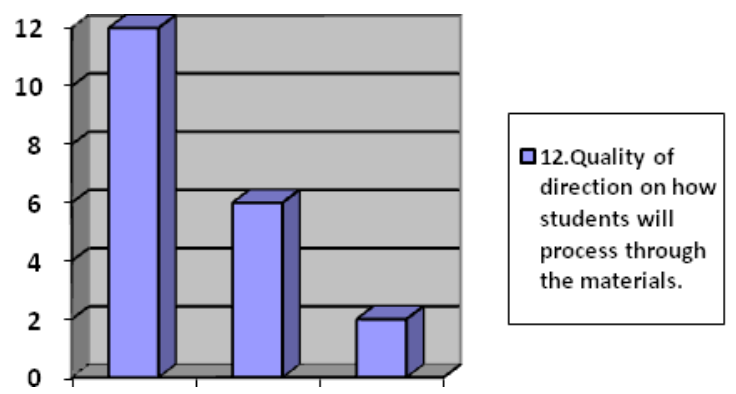

Figure 12: Quality of direction

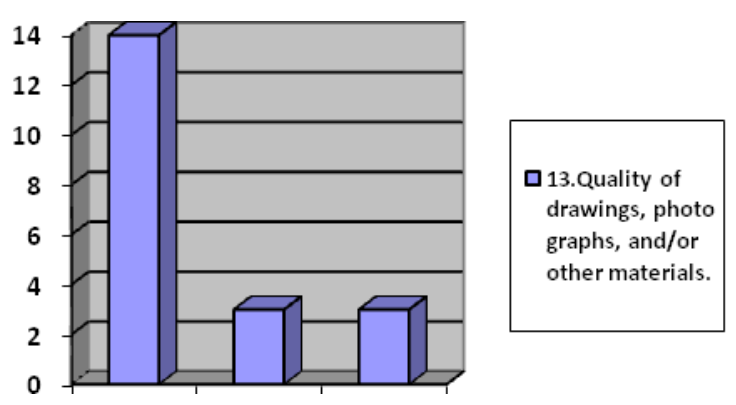

Figure 13: Quality of drawings, photographs, and/or other materials 

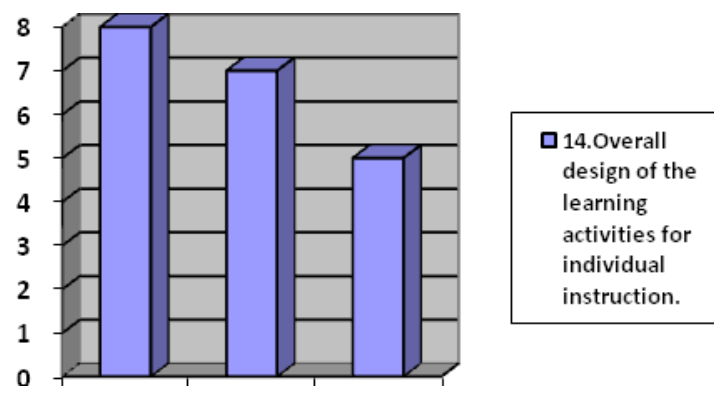

Figure 14: Overall design of the learning activities for individual instruction.
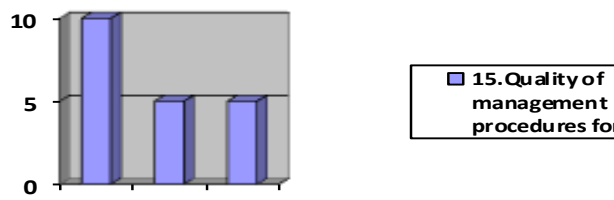

Figure 15: Quality of management procedures for teacher

Table 2Analysis of Data

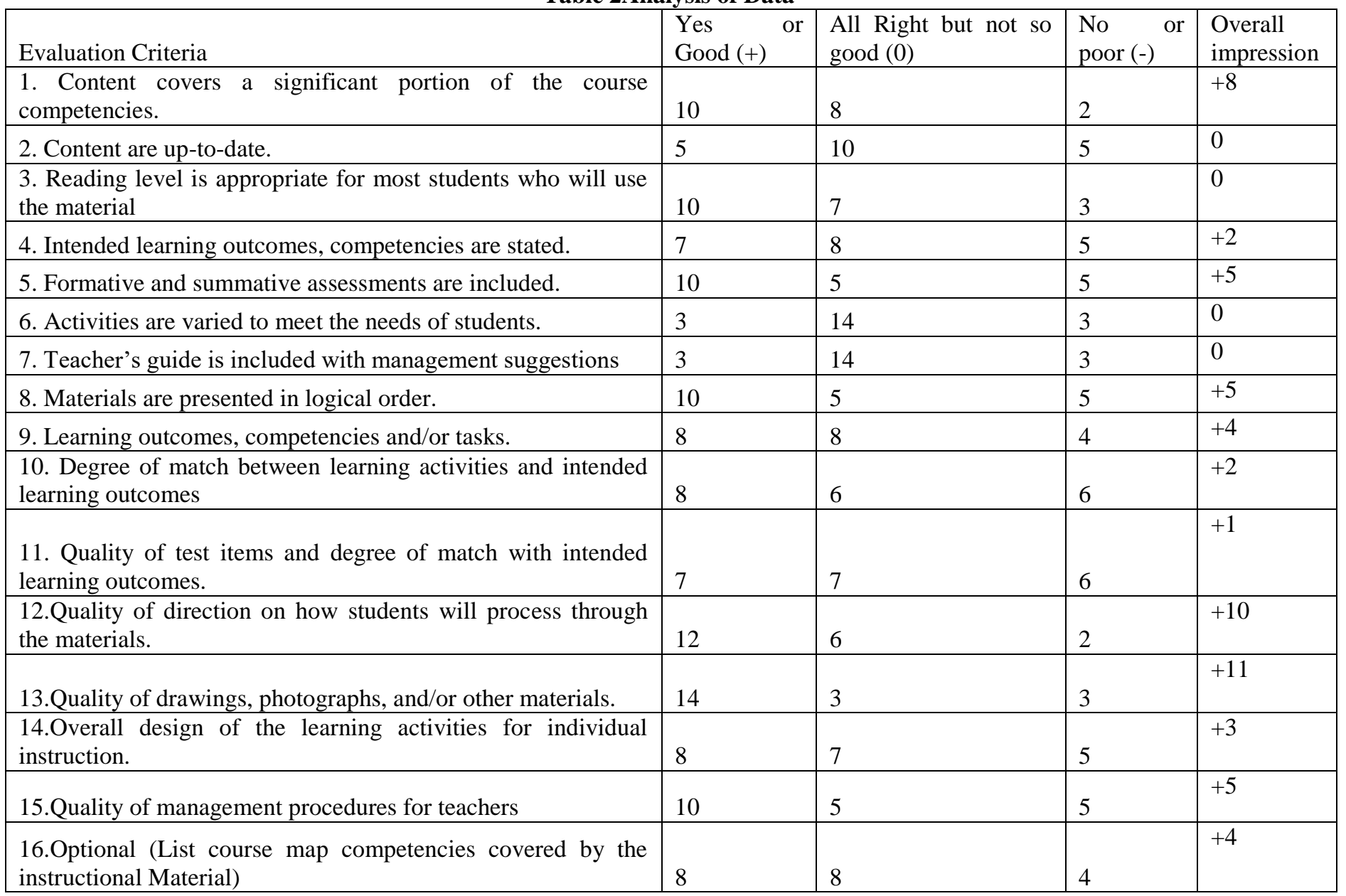




\section{Findings}

1. Contents cover a significant proportion.

2. Contents are not up to date

3. Reading levels of students who use materials is are not appropriate.

4. Intended learning outcomes and competencies statement is poor.

5. Acvities are not varied to meet student need.

6. Teacher's guide is not included with management suggestion.

7. Learning outcomes or tasks definition is poor.

8. Degree of match between learning activities and intended learning outcomes is poor

9. Quality of test items and degree of match with intended learning outcomes is poor.

10. Overall design of the learning activities for individual instruction is poor.

11. Course map competencies covered by the instructional Material is poor.

\section{Conclusions:}

According to above analysis present curriculum needs immediate update in the areas of contents, materials given to students, statement of competencies, activities planned. Outcomes are to be clearly framed. Individual instruction is poor due to lack of learning activities. Tests are not planned keeping in view of learning outcomes. Instruction materials poorly cover course mapping competencies.

Management, student and teacher are most important in curriculum design and innovation. Management should focus on training the teacher in outcome based education. All groups should be fully involved in curriculum design. Individual teacher learning activities are to be facilitated by management on a regular basis. Teacher's learning plays a very important role in curriculum design and curriculum implementation. This benefits the student.

\section{References}

Rizza Linn Labastida, "Curriculum Evaluation and the teacher”, 17/10/2016. Module 5, Chapter 4, Evaluating the curriculum, paper, www.Slidershare net,.

KBS survey tool, Kaplan Business School, Australia

KlodianaKolomitro, Jenna Inglese, MaiaIdzikowski, (2017),

Course Design Hand Book, Centre for Teaching and Learning, Queens University, 